\title{
Research on Driver's Seating Position Based on Chinese Human Characteristics
}

\author{
Liping Liu, Weinan Ju, Hongwei Liu
}

\begin{abstract}
Driver's seating position is an important factor affecting driving posture and comfort. Chinese drivers were took as the research object in this paper. Driving posture characteristics were collected through experiments. Parameters of the driver's seating position were extracted. By analyzing the horizontal and vertical seating position, the SgRP curve equation of the Chinese driver was obtained. This research will provide a basis for the positioning of car seats and a reference for the study of driver's seat position preference.
\end{abstract}

Index Terms-Chinese human characteristics, seating position, SgRP curve equation.

\section{INTRODUCTION}

Driver's spatial position and driving posture in the cab are largely determined by the seat, and other related devices must be coordinated and deployed around the driver to ensure that various functions required for driving can realized comfortably and conveniently. Therefore, the seat is the most important factor affecting the driver's comfort among the factors in the layout of the cab. It is found that there is a linear relationship between the horizontal position and the vertical position of the driver. The Society of Automotive Engineers (SAE) launched the "SAE J1517 Driver Selected Seat Position" standard in 1985 [1], in which, the seat position selected by the driver is specified, and the functional relationship between the horizontal position and the vertical position of the driver's seat is proposed. This function curve can be called SgRP curve. This standard specifies different percentile SgRP curves. As time goes on, the standard is constantly updated, the latest is 2010 version. However, SAE SgRP curve is based on US human body data and may not be applicable to other countries. Therefore, in order to explore the relationship between the driver's seating horizontal position and vertical position of Chinese, the driver's seating position of Class A vehicles is studied in this paper based on Chinese human body characteristics data.

\section{EXPERIMENTAL DESIGN AND DATA ACQUISITION}

\section{A. Subjects}

The experimental subjects were selected according to the

Liping Liu, China Automotive Technology \& Research Center Co., Ltd. Tianjin, China

Weinan Ju, China Automotive Technology \& Research Center Co., Ltd. Tianjin, China

Hongwei Liu, China Automotive Technology \& Research Center Co., Ltd., Tianjin, China characteristics of Chinese body height, weight and age, so that the distribution of subjects basically conformed to the overall characteristics of the Chinese population. 500 drivers including 258 males and 242 females were selected in this experiment. The height was ranging from $148 \mathrm{~cm}$ to $181 \mathrm{~cm}$, with an average height of $162.4 \mathrm{~cm}$. The weight was ranging from $40 \mathrm{~kg}$ to $92 \mathrm{~kg}$, with an average weight of $65.7 \mathrm{~kg}$. The age was ranging from 17 to 70 years old, with an average age of 43.5 years old.

\section{B. Experimental conditions}

(1) Experimental vehicles

The general layout parameters of the selected sample vehicles covered the current mainstream vehicle's human-machine parameters on the market, including American, legal, German, Japanese and Korean, domestic etc. They were well sold on the market, with a relatively wide mass base. The driving mileage was not more than $10000 \mathrm{~km}$ to ensure that the seat shape and adjustment function would not be greatly deviated. In this experiment, 8 sample vehicles were selected, including Volkswagen CC, Haval H9, Carola, Passat, Ford sharp, Xiaoke, Volkswagen Golf and Volkswagen tuguan.

(2) Experimental equipment

In this experiment, the vehicles and subjects in the vehicle coordinate system need to be scanned to get the point cloud model. In order to ensure the high quality of point cloud, two sets of scanning equipment were used. One was used to scan the overall structure of the vehicle, and the other was used to scan the driving posture of the human body and the interior and exterior decoration of the vehicle. Both kinds of scanning equipment could identify the points located by the Max-shot global photogrammeter.

1) Max-shot global photogrammeter. It was used to scan the vehicle and establish the vehicle coordinate system.

2) Xing chuang Handy SCAN 700. It was used to scan the interior and exterior decoration of the vehicle. This equipment had high scanning accuracy of $0.002 \mathrm{~mm}$, small size and flexible operation, and could scan some detailed features well.

3) GO SCAN. It was used to scan human body. It was a special equipment for scanning human body, with high scanning accuracy and point cloud accuracy of $0.1 \mathrm{~mm}$. 


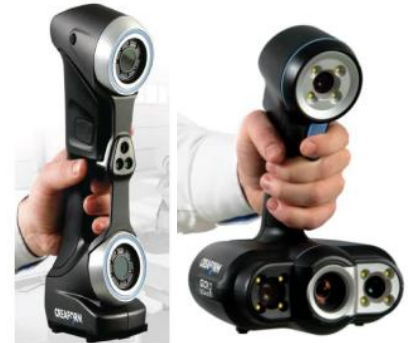

Figure 1 Scanning equipment (left: Xing chuang Handy SCAN 700, right: GO SCAN)

\section{Experimental content}

(1) Information statistics of subjects

Basic information such as sex, age, height, weight, etc. of subjects be counted.

(2) Preparation before scanning

Introduced the data collection process and precautions to the subject, who was required to wear white bodysuits, dark-colored shoes such as white or gray (or put on white shoe covers, sports shoes are recommended), white swimming cap (the hair should not be exposed) and no jewelry. Marked points were pasted at the key feature points of the subject.

\section{(3) Driving posture scanning}

The subject was required to sit in the driving position of the vehicle and adjusted the seat and steering wheel to reach a comfortable position, then wore the seat belt, held the steering wheel with both hands, placed left foot on the footrest, and right foot on the accelerator pedal (no effort to step on the accelerator) and looked ahead to simulate the normal driving condition. The experiment organizer would use the experimental equipment to scan subject's driving posture. Four thousand point cloud models were obtained by scanning the driving posture of 500 subjects in 8 experimental vehicles separately.

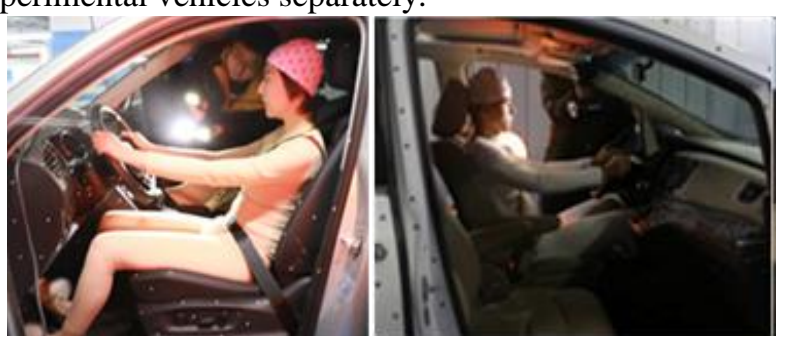

Figure2 Experimental scene

\section{Data preprocessing}

Chinese human body model was constructed in the Human Builder module according to the latest Chinese body size data [2]. Drivers' seating position data were extracted from driving point cloud models using the Chinese human body model. Generally, $H 3 O$ (vertical distance between $\mathrm{H}$ point and heel point of driver) was used as a measure of the driver's vertical seating position, and $X$ (horizontal distance of the driver's $H$ point after the ball of foot reference point) was used as a measure of the driver's horizontal seating position. Incomplete data, unclear scan data, and abnormal data were eliminated. Because the $H 30$ value was usually between $200 \mathrm{~mm}$ and $400 \mathrm{~mm}$, the data outside the interval were deleted. Finally, 3858 groups of experimental data were selected as the final data set for statistical analysis

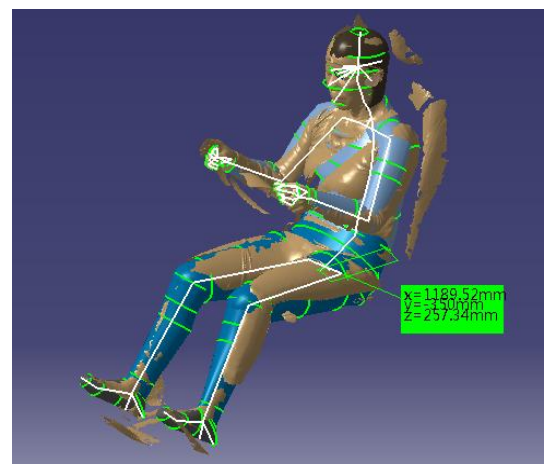

Figure 3 Schematic diagram of Chinese human driving posture data extraction

\section{RESULTS}

\section{A. Normal distribution test}

3858 groups of valid data obtained from the preprocessing are analyzed. Group the data according to $H 30$ value. 40 groups of data sets can be obtained every $50 \mathrm{~mm}$, which are recorded as $X_{1}, X_{2}, \ldots, X_{40}$ respectively. The $H 30$ value corresponding to each data set can be regarded as the average value of $\mathrm{H3O}$ in each interval. The single-sample Kolmogorov Smirnov (K-S) test is used to analyze the distribution of each data set. Analysis results are shown in Table 1. It can be seen that the asymptotic significance of each group is greater than the significance level of 0.05 . Therefore, it can be considered that the data of each group are normal distribution and can be analyzed in the next step.

Table 1 Single sample K-S test results

\begin{tabular}{|c|c|c|c|c|c|c|c|c|}
\hline \multirow[b]{2}{*}{ Group } & \multirow[b]{2}{*}{$\mathbf{N}$} & \multicolumn{2}{|c|}{$\begin{array}{c}\text { Normal } \\
\text { parameter }\end{array}$} & \multicolumn{3}{|c|}{$\begin{array}{l}\text { Most extreme } \\
\text { difference }\end{array}$} & \multirow{2}{*}{$\begin{array}{c}\text { Kolmogorov- } \\
\text { Smirnov Z }\end{array}$} & \multirow{2}{*}{$\begin{array}{c}\text { Asymptotically } \\
\text { significant } \\
\text { (bilateral) }\end{array}$} \\
\hline & & $\begin{array}{l}\text { Mean } \\
\text { value }\end{array}$ & $\begin{array}{l}\text { Standard } \\
\text { deviation }\end{array}$ & $\begin{array}{c}\text { Absolute } \\
\text { value }\end{array}$ & Plus & Minus & & \\
\hline 1 & $\begin{array}{l}2 \\
3 \\
\end{array}$ & \begin{tabular}{|c|}
782.878 \\
3 \\
\end{tabular} & 41.56130 & 0.118 & $\begin{array}{c}0.11 \\
8 \\
\end{array}$ & -0.073 & 0.564 & 0.908 \\
\hline 2 & 3 & \begin{tabular}{|c|}
788.697 \\
3 \\
\end{tabular} & 35.52097 & 0.096 & $\begin{array}{c}0.09 \\
6\end{array}$ & -0.075 & 0.581 & 0.888 \\
\hline 3 & $\begin{array}{l}5 \\
1 \\
\end{array}$ & \begin{tabular}{|c|}
794.503 \\
9
\end{tabular} & 37.41056 & 0.088 & $\begin{array}{c}0.05 \\
8\end{array}$ & -0.088 & 0.627 & 0.827 \\
\hline 4 & $\begin{array}{l}6 \\
9 \\
\end{array}$ & \begin{tabular}{|c|}
797.544 \\
9 \\
\end{tabular} & 35.13305 & 0.078 & $\begin{array}{c}0.06 \\
8\end{array}$ & -0.078 & 0.644 & 0.801 \\
\hline 5 & 6 & \begin{tabular}{|c|}
794.631 \\
9
\end{tabular} & 36.13126 & 0.100 & $\begin{array}{c}0.10 \\
0\end{array}$ & -0.058 & 0.829 & 0.497 \\
\hline & & & & & & & & \\
\hline 40 & 2 & \begin{tabular}{|c|}
750.858 \\
6
\end{tabular} & 41.13191 & 0.134 & $\begin{array}{c}0.10 \\
4\end{array}$ & -0.134 & 0.722 & 0.675 \\
\hline
\end{tabular}

\section{B. Eigenvalue calculation}

Calculate the values corresponding to the typical percentiles of 40 data sets respectively. The calculation method is shown in formula (1). The calculation results are shown in Table 2.

$$
P=\Phi\left(\frac{X_{P}-\mu}{\sigma}\right)
$$

Where, $P$ is the percentile. $X_{P}$ is the horizontal distance of the driver's H-point at the $P^{\text {th }}$ percentile after the ball of foot reference point, in mm. $\mu$ is the mean of $X$ data set. $\sigma$ is the standard deviation of $X$ data set. $\Phi$ represents normal distribution. 
Table 2 values corresponding to percentiles of different

\begin{tabular}{|c|c|c|c|c|c|c|c|c|c|c|}
\hline Group & H30 & $\mu$ & $\sigma$ & $\boldsymbol{X}_{\mathbf{9 7 . 5}}$ & $\boldsymbol{X}_{\mathbf{9 5}}$ & $\boldsymbol{X}_{\mathbf{9 0}}$ & $\boldsymbol{X}_{\mathbf{5 0}}$ & $\boldsymbol{X}_{\mathbf{1 0}}$ & $\boldsymbol{X}_{\mathbf{5}}$ & $\boldsymbol{X}_{\mathbf{2 . 5}}$ \\
\hline 1 & 202.16 & 782.88 & 41.56 & 864.34 & 851.25 & 836.16 & 782.88 & 729.60 & 714.51 & 701.42 \\
\hline 2 & 207.93 & 788.70 & 35.52 & 858.32 & 847.13 & 834.24 & 788.70 & 743.16 & 730.27 & 719.08 \\
\hline 3 & 212.48 & 794.50 & 37.41 & 867.83 & 856.04 & 842.46 & 794.50 & 746.54 & 732.96 & 721.18 \\
\hline 4 & 217.73 & 797.54 & 35.13 & 866.41 & 855.34 & 842.59 & 797.54 & 752.50 & 739.75 & 728.68 \\
\hline 5 & 222.17 & 794.63 & 36.13 & 865.45 & 854.07 & 840.95 & 794.63 & 748.31 & 735.20 & 723.81 \\
\hline \multicolumn{7}{|c|}{$\ldots \ldots \ldots \ldots \ldots \ldots \ldots \ldots$} \\
\hline 40 & 397.50 & 750.86 & 41.13 & 831.48 & 818.52 & 803.59 & 750.86 & 698.13 & 683.20 & 670.24 \\
\hline
\end{tabular}

\section{Regression analysis}

Regression analysis is performed between $H 30$ and $X$ in the same percentile. Taking the 50th percentile as an example, the following analysis results can be obtained:

Table 3 Model summary

\begin{tabular}{|c|c|c|c|c|c|}
\hline $\mathbf{R}$ & \multicolumn{2}{|c|}{ R-square } & Adjust R-square & \multicolumn{2}{|c|}{\begin{tabular}{|c|}
$\begin{array}{c}\text { Standard error of } \\
\text { estimate }\end{array}$ \\
\end{tabular}} \\
\hline 0.922 & \multicolumn{2}{|c|}{0.850} & 0.842 & \multicolumn{2}{|c|}{6.187} \\
\hline \multicolumn{6}{|c|}{ Table 4 Regression coefficient table } \\
\hline & \multicolumn{2}{|c|}{$\begin{array}{c}\text { Unstandardized } \\
\text { coefficient }\end{array}$} & $\begin{array}{c}\text { Standardized } \\
\text { coefficient }\end{array}$ & \multirow{2}{*}{$\mathrm{t}$} & \multirow{2}{*}{ Sig. } \\
\hline & B & $\begin{array}{c}\text { Standard } \\
\text { error }\end{array}$ & Beta & & \\
\hline H30 & 0.384565 & 0.198 & 1.444 & 1.940 & 0.049 \\
\hline $\mathrm{H} 30 * * 2$ & -0.001040 & 0.000 & -2.352 & -3.161 & 0.003 \\
\hline (constant) & 759.795 & 28.988 & & 26.211 & 0.000 \\
\hline
\end{tabular}

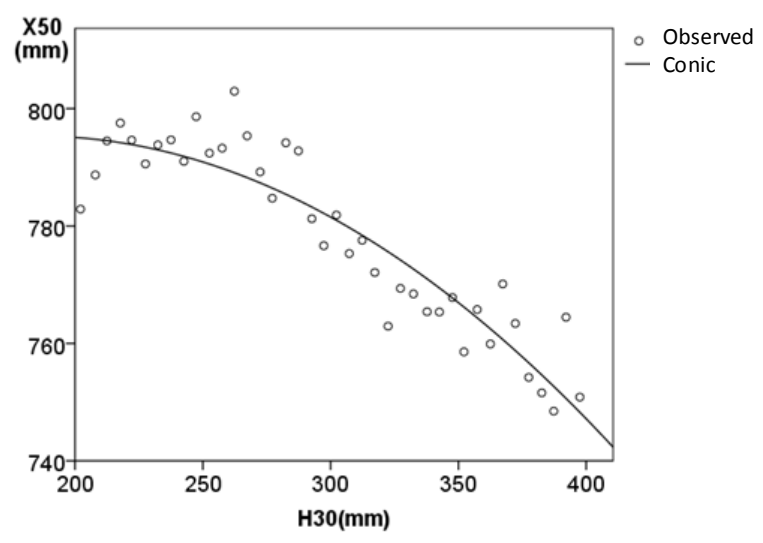

Figure 4 Fitting curve of the model

\section{DISCUSSION}

In this paper, experiment is carried out to collect Chinese human driving posture data. Driver's seating position parameters are extracted and the relationship between driving vertical position and horizontal position is analyzed. It is found that there is a functional relationship between them. By comparing with the 50th percentile SgRP curve equation of American SAE, it is found that, at the same driving height, the horizontal driving position of the Chinese is about $65 \mathrm{~mm}$ ahead of the American, as is shown in figure 5.

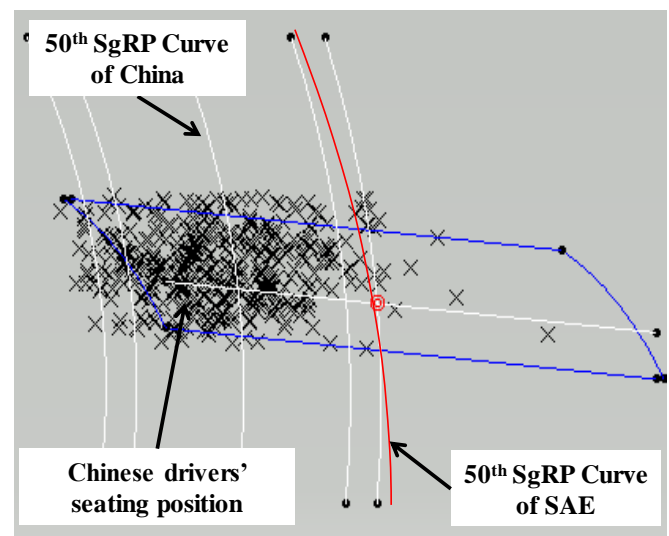

Figure 5 Comparison of SgRP curve between China and SAE

\section{CONCLUSION}

Driver's seating position is the design basis for the seat travel trajectory, which will have a great impact on driving comfort. In this paper, the Chinese SgRP curve equation is obtained by researching the driving position of Chinese human body, which will provide a reference for the design and positioning of the car seat position, and also provide a basis for the research of driver's riding position preference.

\section{REFERENCES}

[1] SAE J1517-1985, Driver Selected Seat Position. USA: SAE International, 1985.

[2] Jindong REN, Automotive Ergonomics. Beijing: Peking University Press, 2010:141-260. 